\title{
Ideal Pattern of Business and IS Alignment for Improving e-Government Services in Saudi Arabia
}

\author{
Sulaiman Abdulaziz Alfadhel ${ }^{1 *}$, Shaofeng Liu1 ${ }^{1}$, Festus O. Oderanti ${ }^{2}$ \\ 1. Plymouth Graduate School of Management, University of Plymouth, Plymouth, UK. \\ 2. Hertfordshire Business School, University of Hertfordshire Hatfield, UK. \\ * Corresponding author. Tel.: +44(0)7478637367; email: Sulaiman.alfadhel@plymouth.ac.uk \\ Manuscript submitted January 10, 2018; accepted March 8, 2018. \\ doi: 10.17706/jsw.14.2.92-106
}

\begin{abstract}
Over the past few years, governments from all over the world are losing general public trust. This lack of public trust presents a significant challenge to public officers, citizens and politicians as it decreases community confidence in public officers and political performance and generates disappointment with community support and services. Alignment is a process where every stakeholder in the government infrastructure works together to achieve common business objectives. The aim of this paper is to study a comprehensive pattern (strategic, structural, social and cultural) of alignment with the aim of improving government services in Saudi Arabia. The data has been collected from different e-government experts from the Kingdom of Saudi Arabia. Study result indicates that public trust and e-government goals can be attained through establishing strong alignment between information systems (IS) departments and other government agencies.
\end{abstract}

Key words: E-government, Ideal pattern, alignment, government performance.

\section{Introduction}

The idea of using information systems (IS) in government emerged in the early 1950's and 1960's when computers were used to handle large data and repetitive tasks, for example billing or generating payrolls [1], [2]. These initial IS applications drove the development of IS departments within government operational areas such as marketing, finance, management and administration, with an emphasis on achieving management competence, cost effectiveness and to support other large transactional and decision support systems [2].

The literature shows that to address the complexities involved in the use of IS to support the public sector, researchers introduced the term e-government [4]-[7]. e-government is the use of information and communication technologies (ICTs) to improve the activities of public sector organisations. Some researchers restrict their definition of e-government to the Internet and its applications only, or to the establishment of communication between government actors and other external groups [5], [6]. In this paper, we focus on the first definition of e-government as this definition covers all the components of alignment in the context of e-government: what needs to be included in the e-government infrastructure? who are the e-government actors and what are their needs? what services does the government provide? and how can IS be used effectively?

Alignment is the process where the IS department and other government agencies work together to accomplish the administrative goals of the government. However, to address these alignment issues, it is important to study the comprehensive pattern of alignment, such as strategy alignment between business and IS, structural alignment between business and IS, social alignment between business and IS, and 
cultural alignment between business and IS [8]-[11]. The literature shows that researchers have only studied two patterns of alignment, that is, business and IS strategies, and business and IS structure [12]. Therefore, it is important to study the comprehensive pattern of alignment [18], as e-government infrastructure is vast with multiple actors involved and different resources are used to run the infrastructure successfully [8]-[11]. The aim of this paper is to study the comprehensive pattern of business and IS alignment in the context of achieving e-government business goals and objectives effectively.

\section{Related Work}

The term e-government incorporates the utilization of IS and ICT in order to provide the effective and efficient delivery of governmental policies and services to local businesses, people, and other agencies in the government [13]. Several researchers [14]-[17], [23]-[25] in the field of e-government argue that the successful use of information systems and its adoption in the government sector can provide a likely benefit for local businesses, citizens and other agencies of the government. Previous research techniques in this area only emphasise one or two of these aspects, that is, structural, strategic or cultural, in relation to the alignment of business and information systems, as shown in Table 1. This paper investigates four aspects (strategic alignment, structural alignment, social alignment and cultural alignment) of alignment between information systems departments and other government agencies. These aspects of alignment are considered to be a pattern of alignment [12].

Table 1. Related Work

\begin{tabular}{|c|c|c|c|c|c|c|c|c|c|}
\hline \multirow[t]{2}{*}{ Authors } & \multicolumn{6}{|c|}{$\begin{array}{l}\text { Alignment fit between business and Information } \\
\text { Systems }\end{array}$} & \multirow[t]{2}{*}{$\begin{array}{l}\text { Alignment } \\
\text { Aspect }\end{array}$} & \multirow{2}{*}{$\begin{array}{l}\text { escription } \\
\text { Descripti }\end{array}$} & \multirow{2}{*}{$\begin{array}{c}\text { Do } \\
\text { mai } \\
\text { n }\end{array}$} \\
\hline & $\begin{array}{l}\text { Business } \\
\text { strategy }\end{array}$ & $\begin{array}{l}\text { Business } \\
\text { structure }\end{array}$ & $\begin{array}{c}\text { Business } \\
\text { culture }\end{array}$ & $\begin{array}{c}I S \\
\text { strategy }\end{array}$ & $\begin{array}{c}I S \\
\text { structure }\end{array}$ & $\begin{array}{c}\text { IS } \\
\text { culture }\end{array}$ & & & \\
\hline $\begin{array}{l}\text { Xiaoying } \\
\text { et al. } \\
\text { (2008) }\end{array}$ & $\sqrt{ }$ & $x$ & $x$ & $x$ & $\sqrt{ }$ & $x$ & $\begin{array}{c}\text { Strategic } \\
+ \\
\text { Culture }\end{array}$ & $\begin{array}{l}\text { The study } \\
\text { presents } \\
\text { the } \\
\text { measure } \\
\text { ment of }\end{array}$ & $\begin{array}{c}\text { Local } \\
\text { organ } \\
\text { izatio } \\
\text { ns }\end{array}$ \\
\hline $\begin{array}{l}\text { Bergeron } \\
\text { et al. } \\
(2004)\end{array}$ & $\sqrt{ }$ & $\sqrt{ }$ & $x$ & $\sqrt{ }$ & $\sqrt{ }$ & $x$ & $\begin{array}{c}\text { Strategic } \\
+ \\
\text { Structural }\end{array}$ & $\begin{array}{l}\text { The study } \\
\text { examines } \\
\text { the impact } \\
\text { of } \\
\text { alignment }\end{array}$ & $\begin{array}{l}\text { Intern } \\
\text { ationa } \\
\quad 1 \\
\text { organ } \\
\text { izatio } \\
\end{array}$ \\
\hline $\begin{array}{c}\text { Hirschhei } \\
m \\
\text { andSabhe }\end{array}$ & $\sqrt{ }$ & $\sqrt{ }$ & $x$ & $\sqrt{ }$ & $\sqrt{ }$ & $x$ & $\begin{array}{c}\text { Strategic } \\
+ \\
\text { Structural }\end{array}$ & $\begin{array}{l}\text { The study } \\
\text { describes } \\
\text { the }\end{array}$ & $\begin{array}{l}\text { Local } \\
\text { organ } \\
\text { izatio }\end{array}$ \\
\hline $\begin{array}{l}\text { Silvius } \\
\text { et al. } \\
(2013)\end{array}$ & $x$ & $x$ & $\sqrt{ }$ & $x$ & $x$ & $\sqrt{ }$ & Cultural & $\begin{array}{l}\text { The study } \\
\text { examines } \\
\text { the cultural } \\
\text { fit between }\end{array}$ & $\begin{array}{l}\text { Intern } \\
\text { ationa } \\
\text { l } \\
\text { organ }\end{array}$ \\
\hline $\begin{array}{l}\text { Ullah } \\
\text { and Lai, } \\
2013\end{array}$ & $x$ & $\sqrt{ }$ & $x$ & $x$ & $\sqrt{ }$ & $x$ & Structural & $\begin{array}{l}\text { The study } \\
\text { results } \\
\text { indicate }\end{array}$ & $\begin{array}{l}\text { Local } \\
\text { organ } \\
\text { izatio }\end{array}$ \\
\hline $\begin{array}{l}\text { Luftman } \\
\text { et al. } \\
(1999)\end{array}$ & $x$ & $x$ & $\sqrt{ }$ & $x$ & $x$ & $\sqrt{ }$ & Cultural & $\begin{array}{l}\text { The study } \\
\text { empirically } \\
\text { proves that } \\
\text { achieving } \\
\text { alignment } \\
\text { is } \\
\text { evolutiona }\end{array}$ & $\begin{array}{l}\text { Gover } \\
\text { nmen } \\
\text { t }\end{array}$ \\
\hline
\end{tabular}




\section{Research Methodology}

This research was conducted using an interview-based technique to identify and measure the ideal pattern of alignment between business and IS in the context of the e-government sector. We have first completed comprehensive literature review on the process of alignment and e-government sector and identified alignment factors from literature, which have been used to proposed alignment framework. However, it is important to validate factors belonging to the framework, this paper presents a qualitative study in the process of alignment and e-government sector.

This section discusses the proposed research method to identify the ideal pattern of alignment along with the instrument design and data analysis.

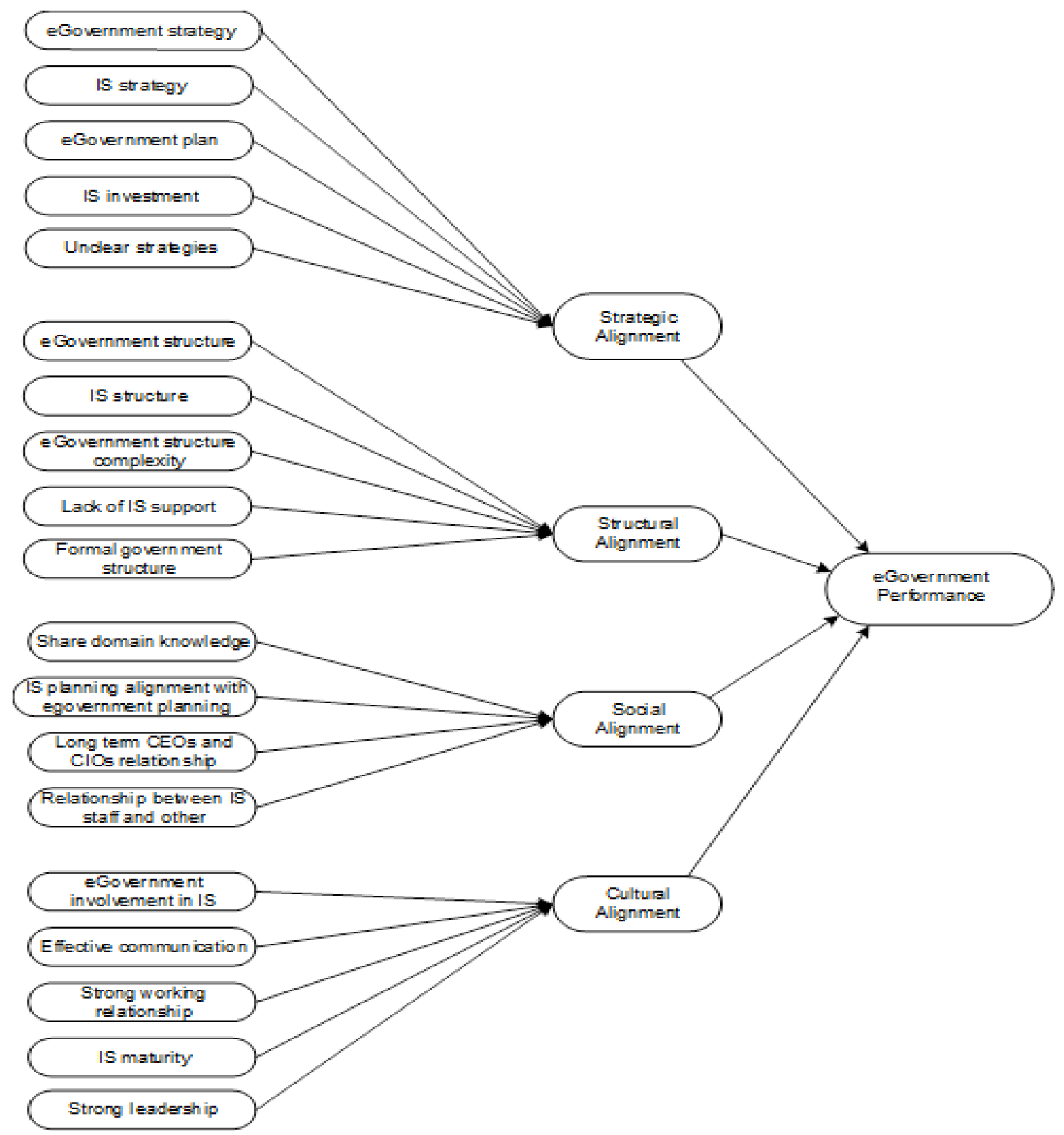

Fig. 1. Method for ideal pattern of alignment.

\subsection{Research Methods and Thematic Analysis}


This paper qualitatively investigates the ideal pattern of alignment and its benefits to the e-government sector. The qualitative method is suitable for this research due to the following reasons: 1) the method allows to develop further testing the research; 2) helps to understand the e-government experts viewpoint on alignment; 3) uncover missing factors of alignment. This work is divided into two measures: phase 1 details the theoretical background and gives an overview of alignment as well as presents the related work; and phase 2 describes the research method adopted in this paper. The method employed in this work investigates patterns of alignment, namely: strategic alignment, structural alignment, social alignment and cultural alignment between IS departments and other agencies in the eGovernment sector. Each pattern of alignment is further categorized into several factors as shown in Fig. 1 and the loading of factors on their related pattern of alignment is tested. Finally, we test the fit of all four alignment patterns on the performance of alignment. This type of alignment fit is found in the information system literature. For example, Henderson and Venkatraman (1993) identified the importance of aligning internal and external enterprise domains and the internal side of the enterprise domain. The authors included the following factors: IT strategy and IT infrastructure and processes and on the external side: business strategy and organizational infrastructure and processes.

For the analysis, the initial literature review on the process of alignment between business and information systems emphasized the requirement for a reasonable review of the existing literature so that research stream can be identified, analyzed and distributed (Daly et al., 1997). Thematic analysis approach has been identified as a suitable approach to achieve this, as its determination is to examine for developing themes linked with the concept in question. Thematic analysis approach offers a hypothetically supple technique to qualitative study or research that goals to classify and describe patterns (Daly et al., 1997); Braun and Clarke, 2006). Moreover, the thematic analysis approach allows for the mixture and conversion of key ideas within qualitative study; conversion is taken as the procedure of identifying comparable ideas in studies wherever they might be uttered using dissimilar words (Daly et al., 1997; Thomas and Harden, 2008).

In addition to this thematic analysis includes identifying research themes through reading data carefully and rereading collected data (Rice and Ezzy, 1999). Braun and Clarke (2006) discuss a research theme in the context of capturing key ideas among the data in relation to finding data pattern and key concept in the research question. Patton (1990) advises that the logical process of the approach of thematic analysis must effort to theories, but should not only based on the implication of patterns, also the patterns wider meanings and suggestions.

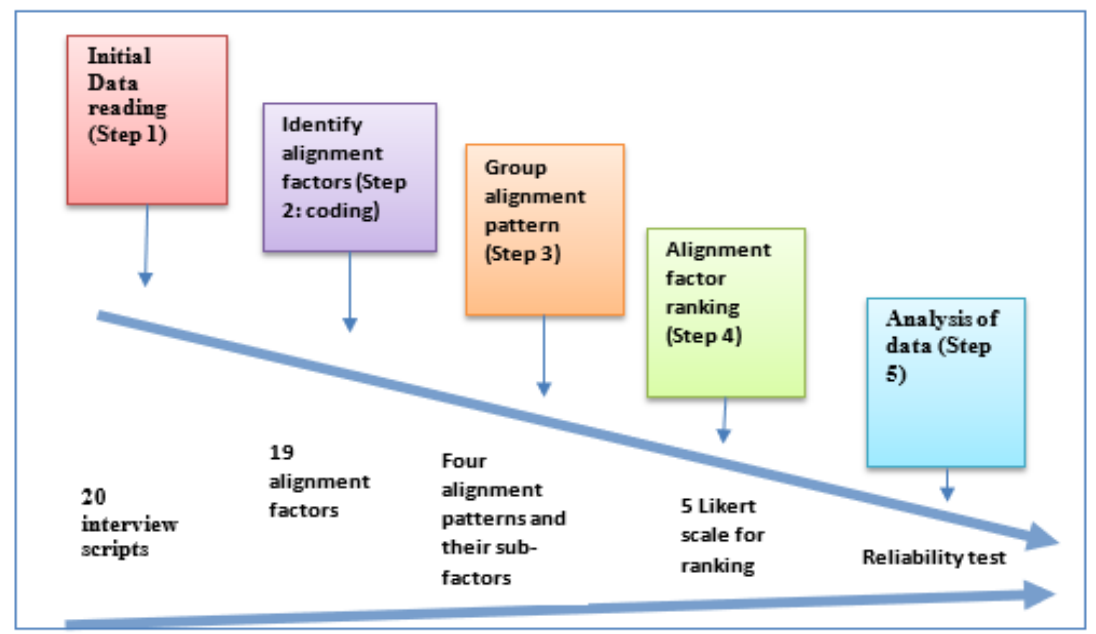

Fig. 2. Thematic analysis approach. 
In our case thematic analysis approach has been divided into five steps, as shown in Fig. 2. Where, step 1: Initial data reading: once we received interview scripts, we then read interview data line by line. Step 2: Coding, in this step we identify the common pattern among the collected data, after identifying the alignment factors in the context of four patterns of alignment. Step 3: Group pattern: one we identify sub-factors of each alignment pattern, we then group them in their desire pattern of alignment. Step4: alignment factor ranking: once factors have been identified and grouped them with their desire alignment pattern, we then ranked each sub-factor of alignment based on the five Likert scale. Step 5: Data analysis and discussion. In this step we apply reliability test to identify the relationship between each pattern of alignment.

For the analysis of our first objective, we grouped each pattern of alignment into sub-factors, as shown in Fig. 1. For each pattern, we apply Cronbach's alpha to measure the internal reliability or consistency among the factors and identify how closely associated a set of factors is as a group or pattern. A reliability coefficient of 0.70 or higher is considered acceptable in most technical and scientific research studies (18, 19). Cronbach's alpha is calculated as follows:

$$
\alpha=\frac{N \cdot \bar{c}}{\bar{v}+(N-1) \cdot \bar{c}}
$$

where $N$ represents the number of factors, c-bar represents the average inter-item covariance between the factors and v-bar represents the sum of the average variance. If we increase the number of factors, Cronbach's alpha values also increase. Moreover, if the average inter-item relationship is low, the alpha value will also be low. However, if the average inter-item relationship increases, the value of Cronbach's alpha also increases.

Table 2. Demographic Data

\begin{tabular}{|c|c|c|}
\hline Participants' Role & $\begin{array}{l}\text { Years of } \\
\text { experience }\end{array}$ & Ministry in Saudi Arabia \\
\hline System analyst & 10 & Interior Ministry \\
\hline Information System manager & 5 & Foreign Affairs Ministry \\
\hline IT support manager & 6.5 & Health Ministry \\
\hline Business manager & 8 & Labour and Social Affairs \\
\hline IS manager & 9 & National Anti-comption Commission \\
\hline Finance manager & 4 & Interior Ministry \\
\hline IT analyst & 6.5 & Petroleum and Mineral Resources \\
\hline System manager & 11 & Justice Ministry \\
\hline IS engineer & 3.5 & Housing Mrnistry \\
\hline IT manager & 8 & Environment Water \& Agriculture Ministry \\
\hline Application developer & 4 & Commerce and Investment \\
\hline Technical support officer & 10 & Defence and Aviation \\
\hline Business analyst & 6 & Commerce and Investment \\
\hline Database administrator & 11 & Civil Service Ministry \\
\hline $\begin{array}{l}\text { Government consultant for information } \\
\text { system department }\end{array}$ & 12 & Commerce and Investment \\
\hline Network administrator & 5 & Interior Ministry \\
\hline Data analyst & 4.5 & Commerce and Investment \\
\hline Technology consultant & 7 & Education Ministry \\
\hline IS security manager & 5 & Council of Saudi Chambers \\
\hline Management manager & 10 & Interior Ministry \\
\hline
\end{tabular}




\subsection{Sample Data and Data Collection}

A purposeful sampling technique has been used to approach and collect data from the e-government experts. We first approached e-government experts in Saudi Arabia and requested them to participate in the study. We then forwarded the interview questions to the experts who agreed to participate. A qualitative study was conducted to collect the data and for this, a total of 35 business and IS experts from the Saudi Arabian Ministry were approached and 20 agreed to participate. The interview template comprised two key sections. In section 1, we asked the participants about their education, skills, experience and their organizations to ensure the participants had relevant knowledge in the area of e-government and alignment. In section 2, the participants were asked about the suitability and benefits of alignment between IS departments and other agencies in the e-government sector for the government of Saudi Arabia. Table 2 depicts the participants' roles, their experience and the ministry in which they work.

\subsection{Measurement}

The measures of the four patterns of alignment and e-government performance were taken from the business and management and e-government literature, and organization theory [18]. The idea of fit has been used to identify the relationships between the factors included in each pattern of alignment and the loading of each pattern of alignment on e-government performance. This research refers to the correlation between the following patterns of alignment: business and IS strategy, business and IS structure, business and IS culture, and business and IS structure.

\subsubsection{Business and IS strategy alignment}

For the purposes of this research, the concept of the business strategic direction of business organizations was assumed to measure business strategy. This concept denotes to apprehend as different to projected strategy, emphases on the "development of resource pattern" that organizations adopt to achieve their business goals and objectives, is defined at the business unit level, and espouses a holistic rather than a practical viewpoint. IS strategy is similar to business strategy although IS strategy reports on IS resources [18], [26]. Based on the thematic analysis result, strategic alignment between IS and other agencies in the government, the strategic pattern of alignment is grouped into five components in order to measure strategic alignment in the e-government sector: The strategic alignment components are [18], [19], e-government strategy, IS strategy, existing and future plan of e-government, government investment in IS and e-government strategy which is unclear to the IS team.

\subsubsection{Business and IS structural alignment}

It is costly for a government to have a large number of managerial workers and controls. Consequently, it is vital to eliminate meaningless managerial work within the e-government structure $[28,18]$. A structure defines how government agencies, departments, people and processes are connected and interrelated with each other so that the government's goals are achieved effectively.

The structural pattern of alignment is the most commonly used in business organization philosophy and IS studies. Based on the thematic analysis result structural alignment between IS and other agencies in the government, the structural pattern of alignment is grouped into the following five components in order to measure structural alignment in the e-government sector[18]: e-government and IS structures, the complexity of the e-government structure that could impact alignment performance, a lack of IS support from the government structure and an informal e-government structure.

\subsubsection{Business and IS social alignment}

Social alignment in the government encompasses several components, for example, organizational lifestyles, taxes and the standards that define the culture in which government business operates. This dimension of alignment influences the capability of the government to gain resources, provide services and 
implement processes that improve business performance [28]-[30] Based on the thematic analysis result social alignment between IS and other agencies in the government, the social pattern of alignment is grouped into four components in order to measure social alignment in the e-government sector. The social alignment components are [18], [29], [30]: share domain knowledge among IS and other agencies in the government infrastructure, the involvement of the government's governing body in IS planning, the relationships between the CEOs and the CIOs, and relationship between the IS team and the people from other agencies in the government sector.

\subsubsection{Business and IS cultural alignment}

Culture in the government sector is made up of a variety of dissimilar individuals, where every person's habits and emotional ambitions to attain goals through work. Nonetheless, everyone's goal and emotional drives are different. This combination of people from different cultural backgrounds with different emotions may impact the overall performance of the government; consequently, it is necessity for the government to have strong management that aligns all these people in a way that business goals and objectives are successfully attained [22].

Table 3. Descriptive Data Analysis

\begin{tabular}{|c|c|c|c|c|}
\hline Alignment Patterns & Minimum & Maximum & Mean & Std. Deviation \\
\hline \multicolumn{5}{|l|}{ Strategic alignment } \\
\hline e-govern_strategy & 3 & 5 & 4.35 & .671 \\
\hline IS_strategy & 4 & 5 & 4.30 & .470 \\
\hline e-government_plan & 3 & 5 & 4.25 & .550 \\
\hline IS_Investment & 3 & 5 & 4.40 & .598 \\
\hline Unlcear_eGovern_strategy & 3 & 5 & 4.45 & .686 \\
\hline \multicolumn{5}{|l|}{ Structural Alignment } \\
\hline e-government_structures & 4 & 5 & 4.70 & .470 \\
\hline IS_structures & 4 & 5 & 4.75 & .444 \\
\hline e-govern_infra_complexity & 4 & 5 & 4.55 & .510 \\
\hline Lack_of_IS_Support & 4 & 5 & 4.55 & .510 \\
\hline Informal_e-govern_structure & 3 & 5 & 4.60 & .681 \\
\hline \multicolumn{5}{|l|}{ Social Alignment } \\
\hline Share_domain_knowledge & 4 & 5 & 4.60 & .503 \\
\hline IS_planning_e-govern_agencies & 3 & 5 & 4.55 & .605 \\
\hline CEOs_CIOs_relationship & 3 & 5 & 4.60 & .598 \\
\hline Relationship_IS_and_other & 3 & 5 & 4.20 & .616 \\
\hline \multicolumn{5}{|l|}{ Cultural alignment } \\
\hline e-govern_invlovement_in_IS & 2 & 5 & 4.25 & .851 \\
\hline effective_communication & 2 & 5 & 4.00 & .725 \\
\hline Working_relationship & 2 & 5 & 4.15 & .875 \\
\hline IS_maturity & 2 & 5 & 4.00 & .795 \\
\hline Strong_leadrship & 3 & 5 & 4.20 & .616 \\
\hline Alignment & & & 4.85 & .366 \\
\hline Strategic_alignment & 4 & 5 & 4.65 & .489 \\
\hline Structural_alignment & 4 & 5 & 4.65 & .489 \\
\hline Social_alignment & 4 & 5 & 4.55 & .510 \\
\hline Cultural_alignment & 4 & 5 & 4.85 & .366 \\
\hline
\end{tabular}

The culture in IS departments has been studied by researchers since the early days of the information and communication technology discipline. In early research, culture in the field of IS was studied in terms of two components: values and beliefs [31]. However, based on the thematic analysis result culture has comprise several components in the context of alignment [22], [29]: the involvement of e-government management in the IS department, the communication gap between IS and other agencies in the government, the working relationship among all staff members, the maturity of IS in the government infrastructure, and the 
degree of cultural alignment between IS leaders and leaders from other agencies..

\subsubsection{E-government performance and alignment as fit}

E-government is not a single entity, rather it has several levels and departments, and each level must be aligned to enhance government performance. The literature on information systems management defines the performance of e-government from numerous perspectives [32]. Based on the thematic analysis result, business performance has been selected to measure performance in the e-government environment. This includes indicators such as government projects and return on investment, capital return and government profit per share, government future plans and market share.

In order to identify and examine the relationships between all these patterns of alignment and their impact on government performance, it is significant that every pattern must fit with each other [27]. The literature describes several types of fit methods: co-variation, mediation, gestalts, moderation, matching and reliability as a fit [18], [19]. For this study, reliability as a fit has been selected. It is used to measure the reliability scale and identify the relationships between selected items in the scale.

Patterns of alignment and e-government management researchers have projected a subjective method to measure the performance of businesses [31], [32]. This type of method is more suitable in a situation where businesses have unreliable or unavailable financial data. In this research, people from top management in e-government were asked to indicate on a 5-point Likert scale how their department or organization performed against each pattern of alignment. The descriptive statistics of the research components are presented in Table 3. The data result in Table 3 shows the importance of each selected pattern of alignment and how these patterns result varies from one another.

\section{Results and Discussion}

In this study, after we get the ranking of each factor of alignment in the context of their pattern of alignment we then apply a five point Likert scale, where 1 means "Strongly disagree", 2 means "Disagree", 3 means "Neutral", 4 means "Agree", and 5 means "Strongly agree". After collecting the responses, the final interview template were then divided according to the participants' role and their organizational structure. To cross-validate the rank of each nominated factor and to achieve the aim of this research, we used statistical mean value, standard deviation, minimum, maximum and arithmetical reliability where the mean value is used to classify the average knowledge of alignment in the context of e-government. Standard deviation is used to classify the spread of rank of the factors in a selected sample of interview template. Minimum value represents the lowest rank in the sampler. Maximum represents the highest rank factors in the sample and Cronbach's alpha is used as the reliability statistic to measure internal reliability or consistency among the factors and identify how closely associated a set of factors is as a group or pattern.

\subsection{Ideal Pattern of Alignment}

Strategic pattern of alignment: The strategic alignment between IS and other agencies in the context of eGovernment is grouped into five factors which have been derived from the literature review: 1) involvement of IS in the formulation of e-government strategy, 2) involvement of government management in the formulation of IS strategy, 3) e-government existing and future plans for the development of alignment, 4) the amount of government investment on IS and 5) unclear e-government strategy among the IS staff. The first reliability test in this alignment pattern indicates the alpha coefficient for five factors is 0.68 , suggesting that the strategic alignment factors have relatively low internal consistency. However, after removing the fifth factor, as shown in Table 4, the alpha coefficient for the four factors is 0.71 , which indicates the remaining four factors of strategic alignment have relatively high internal consistency as shown in Figure 3. As a reliability coefficient of 0.70 or higher is considered to be acceptable in the field of information systems and social sciences and a reliability coefficient below 0.50 is considered unacceptable 
$(18,19)$, the selected factors have low consistency and interrelationships. In the case of the fifth factor, the coefficient is below 0.50 which is why this factor is removed from the strategic alignment factor and the overall coefficient value increased.

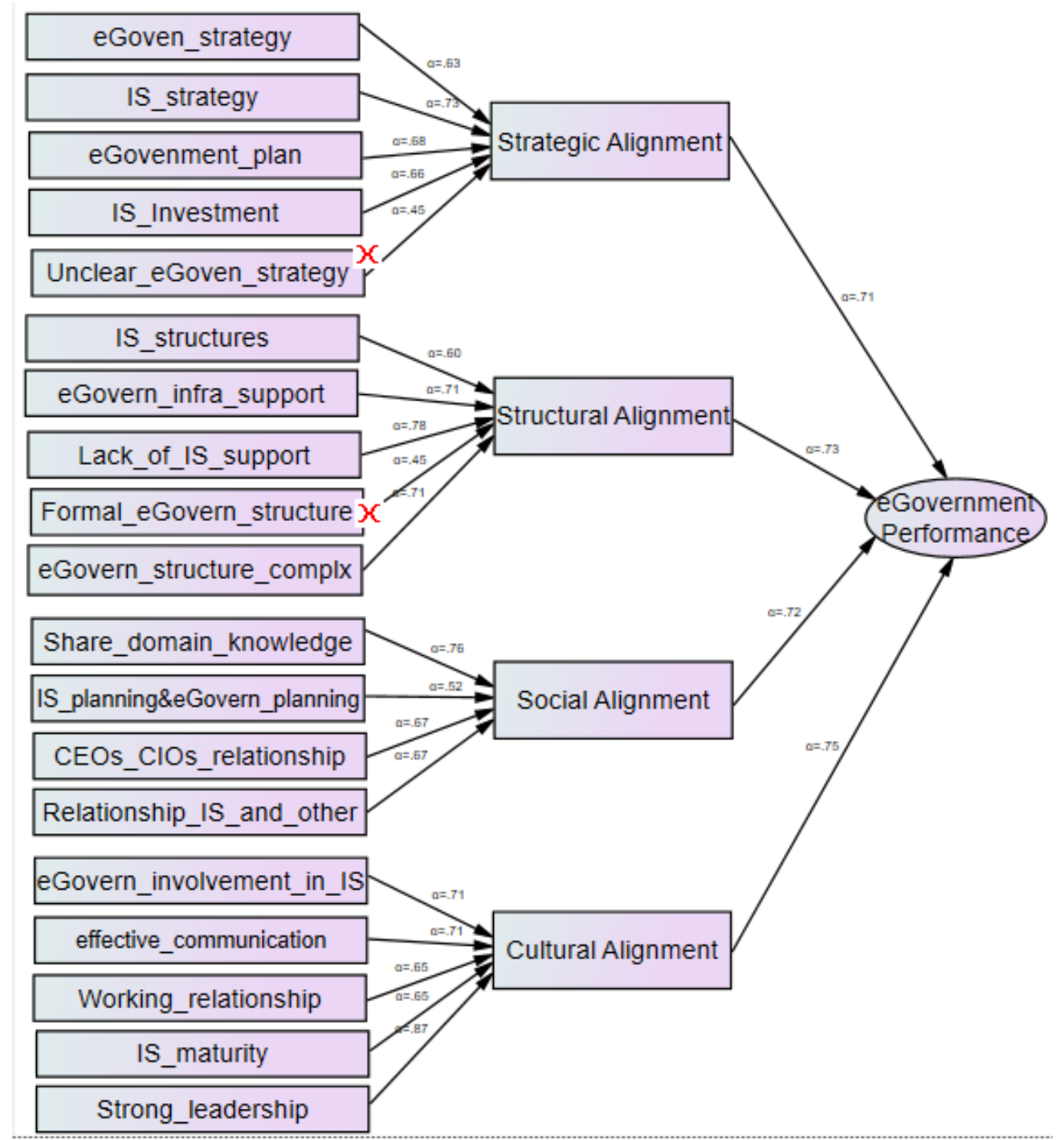

Fig. 3. Framework of alignment based on the thematic analysis result.

This result indicates that strategic alignment in the context of e-government requires organisational design and an external environment is required for the Government to maximize its profitability and effectiveness. In this case, the question is whether the e-government has defined its strategy clearly and the strategy must be understood by every agency in the e-government sector, including the information system department. Strategic alignment in the e-government sector improves collaboration with top management in the government and IS areas. This will help the e-government to set a vision for government outcomes, thoroughly assess opportunities under uncertainty, build a robust fact base, design an unlawful plan, win government stakeholders' support and assess development from plan through to implementation to guarantee that strategies have a long-term impact. However, according to the e-government sector in Saudi Arabia, the factor "unclear e-government strategy" is not an important factor in the Saudi Arabian environment. In the Kingdom of Saudi Arabia, the government is in the early stage of implementing strong working relationships and implementing the eGovernment sector and for this, they have hired many highly 
qualified consultants from developed countries. Therefore, the government is already aware that government strategy must be understood by every stakeholder in the sector.

Table 4. Strategic Alignment Performance

\begin{tabular}{|l|r|r|r|r|r|}
\hline \multicolumn{2}{|c|}{ Total Statistics } \\
factors & $\begin{array}{c}\text { Scale alignment } \\
\text { Mean if } \\
\text { Item } \\
\text { Deleted }\end{array}$ & $\begin{array}{c}\text { Scale } \\
\text { Variance if } \\
\text { Item } \\
\text { Deleted }\end{array}$ & $\begin{array}{c}\text { Corrected } \\
\text { Item-Total } \\
\text { Correlation }\end{array}$ & $\begin{array}{c}\text { Squared } \\
\text { Multiple } \\
\text { Correlation }\end{array}$ & $\begin{array}{c}\text { Cronbach's } \\
\text { Alpha if Item } \\
\text { Deleted }\end{array}$ \\
\hline eGovern_strategy & 17.40 & 2.568 & .548 & .591 & .631 \\
\hline IS_strategy & 17.45 & 3.524 & .256 & .367 & .735 \\
\hline eGovernment_plan & 17.50 & 3.105 & .407 & .258 & .689 \\
\hline IS_Investment & 17.35 & 2.871 & .478 & .258 & .662 \\
\hline Unicear_eGovern_strategy & 16.30 & 2.326 & .45 & .20 & .45 \\
\hline
\end{tabular}

Structural pattern of alignment: the structural alignment between IS and other agencies in e-government has been categorized into five factors: complexity and flexibility of e-government structure, flexibility of IS to manage government requests, e-government infrastructure which is put in place to facilitate information and communication in the government domain, a lack of IS support for government, and informal structure of e-government. The first reliability test in this alignment pattern indicates the alpha coefficient for five factors is 0.66 , suggesting that the structural alignment factors have relatively low internal consistency. However, after removing the "informal e-government" factor, as shown in Table 5, the alpha coefficient for four factors is 0.73 , which indicates the remaining four factors of structural alignment have relatively high internal consistency, as shown in Fig. 3.

Table 5. Structural Alignment Performance

\begin{tabular}{|l|r|r|r|r|r|}
\hline \multicolumn{7}{|c|}{ Total Statistics } \\
\hline Structural alignment & \multicolumn{1}{c|}{$\begin{array}{c}\text { Scale } \\
\text { Mean if } \\
\text { Item } \\
\text { Deleted }\end{array}$} & $\begin{array}{c}\text { Scale } \\
\text { Variance if } \\
\text { Item } \\
\text { Deleted }\end{array}$ & $\begin{array}{c}\text { Corrected } \\
\text { Item-Total } \\
\text { Correlation }\end{array}$ & $\begin{array}{c}\text { Squared } \\
\text { Multiple } \\
\text { Correlation }\end{array}$ & $\begin{array}{c}\text { Cronbach's } \\
\text { Alpha if } \\
\text { Item } \\
\text { Deleted }\end{array}$ \\
\hline eGovernment_structures & 18.45 & 2.050 & .680 & .802 & .665 \\
\hline IS_structures & 18.40 & 2.937 & .751 & .784 & .604 \\
\hline eGovern_infra_complexity & 18.60 & 2.463 & .289 & .634 & .715 \\
\hline Lack_of_IS_Support & 18.60 & 2.358 & .263 & .353 & .788 \\
\hline Informal_eGovern_structure & 18.10 & 1.155 & .684 & .683 & .452 \\
\hline
\end{tabular}

This result indicates that the structural alignment in e-government in Saudi Arabia comprises specific hierarchies, team structures, workflows, reporting working relationships and information streams within the Government infrastructure. Therefore, structural alignment in the context of e-government directly influences the design of both government and information system infrastructures, which occurs to support the e-government structure. E-government experts in the kingdom of Saudi Arabia suggested that understanding how to align e-government structurally can help to implement the ideal infrastructure for government IS and technology needs.

Moreover, according to e-government experts, the Saudi Arabian government has started an e-government program, called "YESSER" in the Arabic language. The aim of this program is to provide world class and secure e-government services so that everyone in the kingdom will be able to access services anytime and anywhere by employing a variety of electronic means. Finally, the experts point out that the 
Saudi Arabian government is based on a formal not informal structure, therefore the "informal eGovernment structure" factor in our model received a low ranking.

Social pattern of alignment: social alignment between IS and other agencies in e-government has been categorized into four factors: shared domain knowledge among IS and other agencies in the government infrastructure, the involvement of the government's governing body in IS planning, relationships between CEOs and CIOs, and relationship between IS team and other people from other agencies in the government sector. The first reliability test in this alignment pattern indicates the alpha coefficient for four factors is .072, suggesting that the social alignment factors have relatively high internal consistency, as shown in Fig. 3. Moreover, Table 6 indicates that every factor in the social pattern of alignment is important and contributes equally.

Table 6. Social Alignment Performance

\begin{tabular}{|l|r|r|r|r|r|}
\hline \multicolumn{7}{|c|}{ Total Statistics } \\
\hline Social Alignment & $\begin{array}{c}\text { Scale } \\
\text { Mean if } \\
\text { Item } \\
\text { Deleted }\end{array}$ & $\begin{array}{c}\text { Scale } \\
\text { Variance if } \\
\text { Item } \\
\text { Deleted }\end{array}$ & $\begin{array}{c}\text { Corrected } \\
\text { Item-Total } \\
\text { Correlation }\end{array}$ & $\begin{array}{c}\text { Squared } \\
\text { Multiple } \\
\text { Correlation }\end{array}$ & $\begin{array}{c}\text { Cronbach's } \\
\text { Alpha if Item } \\
\text { Deleted }\end{array}$ \\
\hline Share_domain_knowledge & 13.35 & 2.239 & .336 & .204 & .761 \\
\hline $\begin{array}{l}\text { IS_planning_eGovern_age } \\
\text { ncies }\end{array}$ & 13.40 & 1.516 & .749 & .581 & .521 \\
\hline CEOS_CIOS_relationship & 13.35 & 1.818 & .509 & .431 & .677 \\
\hline Relationship_IS_an__other & 13.75 & 1.776 & .513 & .294 & .676 \\
\hline
\end{tabular}

This result indicates that all four factors are very important in order to establish social alignment in the e-government sector. Saudi Arabia is a middle eastern country and at this present stage, the country is in an advanced stage of designing and implementing e-government. However, the government still faces several social challenges, which can only be addressed through the social pattern of alignment. These challenges include citizens' security and privacy, lack of awareness and legal structure for online services, people in Saudi Arabia have limited access to the Internet, a lack of IS skills among citizens, and a lack of a relationship between IS management and other agencies in the government. The experts also mentioned that the national e-government program acknowledges the requirement of effective communication between e-government and stakeholders.

Cultural pattern of alignment: cultural alignment between IS and other agencies in e-government has been categorized into five factors: e-government administration involvement in the IS division, communication gap between IS and other agencies in the government, the working relationship between all staff members, the maturity of IS in the government infrastructure, and the cultural alignment of IS top management and top management from other agencies. The reliability test in this alignment pattern indicates the alpha coefficient for four factors is 0.75 , suggesting that the cultural alignment factors have moderately high internal consistency, as shown in Figure 3. Moreover, Table 7 indicates that every factor included in the cultural pattern of alignment is significant and contributes equally in the management of cultural alignment in the e-government sector.

According to the e-government experts, the Saudi Arabian government is currently planning to shift the country's economy from an oil-based production structure to a knowledge-based structure. To do this, the government introduced the idea of e-government to simplify the transfer of services between citizens, other agencies and the government. This acceptance of e-government and e-services is a step towards transmitting the country into an e-society, which will improve the probability of an effective shift towards 
an economy based on knowledge. However, Saudi Arabia is a traditional society where the perception of IS technology and the acceptance of cultural values means that culture is a likely facilitator or inhibitor of e-government acceptance, since culture is a determinant of how citizens respond and successful e-government utilization is not possible without modelling culture properly in the context of e-government acceptance. Therefore, Saudi Arabia government launched a 2030 vision, in this the aim is to align all government stakeholders culturally. Moreover, the experts suggest that every factor of cultural alignment is important and according to them, there is a significant correlation between cultural factors and the adoption of IS in the e-government sector.

Table 7. Cultural Alignment Performance

\begin{tabular}{|l|r|r|r|r|r|}
\hline \multicolumn{7}{|c|}{ Total Statistics } \\
\hline Cultural alignment factors & $\begin{array}{r}\text { Scale Mean if } \\
\text { Item Deleted }\end{array}$ & $\begin{array}{c}\text { Scale Variance } \\
\text { if Item Deleted }\end{array}$ & $\begin{array}{c}\text { Corrected } \\
\text { Item-Total } \\
\text { Correlation }\end{array}$ & $\begin{array}{c}\text { Squared } \\
\text { Multiple } \\
\text { Correlation }\end{array}$ & $\begin{array}{c}\text { Cronbach's } \\
\text { Alpha if Item } \\
\text { Deleted }\end{array}$ \\
\hline eGovern_invlovement_in_IS & 16.35 & 4.976 & .617 & .549 & .716 \\
\hline effective communication & 16.60 & 5.411 & .624 & .553 & .717 \\
\hline Working_relationship & 16.45 & 4.471 & .758 & .594 & .659 \\
\hline IS maturity & 16.60 & 4.674 & .796 & .657 & .650 \\
\hline Strong leadrship & 16.40 & 7.621 & .012 & .178 & .870 \\
\hline
\end{tabular}

\subsection{Ideal Pattern of Alignment and Performance of e-Government}

The second objective of this study is to identify e-government performance against each pattern of alignment: strategic, structural, social and cultural alignment. Ullah and Lai, (2013), suggested that if any government infrastructure followed these four patterns of alignment, its performance should be improved rapidly. e-government performance means saving money on government services, developing trust between government and citizens, protecting citizens' personal information and providing them with fast government services, and developing/maintaining government infrastructure effectively. In this study, we asked the participants if they felt alignment patterns of alignment improved the government's performance. The reliability test in this alignment pattern indicates that the alpha coefficient for four factors is 0.75 , suggesting that the performance of the government will increase, as all four pattern results are moderately high, as shown in Fig. 3. Moreover, Table 8 indicates that every pattern of alignment alpha value is significant and contributes equally to improve e-government performance.

Table 8. Ideal Pattern Alignment Performance

\begin{tabular}{|l|r|r|r|r|}
\hline \multicolumn{5}{|c|}{ Item-Total Statistics } \\
\hline $\begin{array}{l}\text { Ideal pattern of } \\
\text { alignment }\end{array}$ & $\begin{array}{c}\text { Scale Mean if } \\
\text { Item Deleted }\end{array}$ & $\begin{array}{c}\text { Scale } \\
\text { Variance if } \\
\text { Item Deleted }\end{array}$ & $\begin{array}{c}\text { Corrected } \\
\text { Item-Total } \\
\text { Correlation }\end{array}$ & $\begin{array}{c}\text { Cronbach's } \\
\text { Alpha if Item } \\
\text { Deleted }\end{array}$ \\
\hline Strategic_alignment & 13.85 & 1.292 & .701 & .71 \\
\hline Structural_alignment & 14.05 & 1.313 & .408 & .73 \\
\hline Social_alignment & 14.05 & 1.103 & .650 & .72 \\
\hline Cultural_alignment & 14.15 & 1.187 & .506 & .75 \\
\hline
\end{tabular}

e-government experts suggest that Saudi Arabia is still in the developing stage, so many business processes are still manual, hence it is important to use IS to make government business processes fast and reliable, which is only possible if government infrastructure is comprehensively aligned. Moreover, the Saudi Arabian Government launched an e-government program in 2005 based on three building blocks: a united vision of government and action plan, common practices and standards, and a shared infrastructure. A huge amount of government budget was allocated to the e-government programm. However, the government was not able to realize all the benefits from this program due to a lack of alignment in the 
e-government infrastructure. Therefore, the experts strongly suggest the ideal pattern of alignment for the Saudi Arabian government.

In addition to the use of the ideal pattern of alignment to increase government performance, e-government experts in Saudi Arabia also suggest that evaluating and measuring government progress has become a priority for decision makers in the country, as the government continuously seeks to determine the benefit of using IS technologies in government management to enhance internal competency and increase the efficiency of government plans. In order to respond to this request, this ideal pattern of alignment can help to measure every aspect of government infrastructure.

\section{Conclusion}

This paper examined the impact of the ideal pattern of alignment between IS and other agencies in Saudi Arabia. The data was collected from 20 e-government experts from different sectors in the discipline. The ideal pattern of alignment is based on four measures of alignment: strategic, structural, social and cultural alignment, each phase being derived from the alignment and e-government literature. This paper studied this ideal pattern of alignment in the Saudi Arabian e-government sector and the results indicate that the Saudi Arabian Government is keen to obtain the full benefits from IS development, which is why it has started many new and innovative IS programs such as the high budget program "YESSETR" and 2030 Saudi Arabia Government vision. However, the study results show that the government is still not able to achieve its goals due to a lack of alignment between IS departments and other government agencies.

Therefore, e-government experts in the Kingdom suggested that this ideal pattern of alignment can achieve high business performance in terms of growth which leads to increased long-term Government success and this model can help establish internal and external government relationships. This proposed method of alignment could be very useful in the current situation of the Saudi Arabian e-government sector. This study requires further examination using a bigger audience to evaluate the strength of this proposed method of alignment. Our next step is to conduct a quantitative study among e-government users in Saudi Arabia.

\section{References}

[1] Dawes, S. S. (2008). The evolution and continuing challenges of e-governance. Public Administration Review, 68, S86-S 102

[2] Tuya, D., Cook, M. M., Sutherland, M., \& Luna-Reyes, L. F. (2017). The leading role of the government CIO at the local level: Strategic opportunities and challenges. Government Information Quarterly.

[3] Cordella, A., \& Iannacci, F. (2010). Information systems in the public sector: The e-Government enactment framework. Journal of Strategic Information Systems, 19(1), 52-66.

[4] Bannister, F., \& Connolly, R. (2012). Forward to the past: Lessons for the future of egovernment from the story so far. Information Polity. The International Journal of Government \& Democracy in the Information Age, 17(3), 211-226.

[5] Larsson, H., \& Grönlund, Å. (2016). Sustainable eGovernance? Practices, problems and beliefs about the future in Swedish eGov practice. Government Information Quarterly, 33(1), 105-114.

[6] Jones, S. (2012). eGovernment document management system: A case analysis of risk and reward. International Journal of Information Management, 32(4), 396-400.

[7] Juiz, C., Gómez, M., \& Barceló, M. I. (2012). Implementing business/IT projects alignment through the project portfolio approval process. Information Technology Convergence, Secure and Trust Computing, and Data Management.

[8] Morgan, T., Anokhin, S., \& Johnson, E. (2016). Create or appropriate? strategic alignment preference in 
incumbent-new venture alliances and innovation outcomes. In Let's Get Engaged! Crossing the Threshold of Marketing's Engagement Era.

[9] Aslam, N., Nadeem, A., Babar, P. M. E., Aslam, M. T., Naveed, M., Hussain, N., Shehzad, T., Wasim, W., Bao, M. Z., \& Javed, M. (2016). The accuracy of protein structure alignment servers. Electronic Journal of Biotechnology, 20, 9-13.

[10] Gallotti, M., Fairhurst, M. T., \& Frith, C. D. (2017). Alignment in social interactions. Consciousness and Cognition, 48, 253-261.

[11] Heaselgrave, F., \& Simmons, P., (2016). Culture, competency and policy: why social media dialogue is limited in australian local government. Journal of Communication Management, 20(2), 133-147.

[12] Bergeron, F., Raymond, L., \& Rivard, S. (2004). Ideal patterns of strategic alignment and business performance. Information and Management, 41(8), 1003-1020.

[13] Rose, J., Persson, J. S., Heeager, L.T., \& Irani, Z. (2015). Managing e-government: Value positions and relationships. Information Systems Journal, 25(5), 531-571.

[14] Janssen, M., \& Shu, W. S. (2008), December. Transformational government: Basics and key issues. Proceedings of the 2nd International Conference on Theory and Practice of Electronic Governance.

[15] Bannister, F., \& Connolly, R. (2011). Trust and transformational government: A proposed framework for research. Government Information Quarterly, 28(2), 137-147.

[16] Al-Busaidy, M., \& Weerakkody, V. (2009). E-government diffusion in Oman: a public sector employees' perspective. Transforming Government: People, Process and Policy, 3(4), 375-393.

[17] Lips, A. M. B., Gil-Garcia, J. R., \& Sorrentino, M., (2012), Introduction to the transformational government minitrack. Proceedings of the 2012 45th Hawaii International Conference on System Sciences.

[18] Ullah, A., \& Lai, R. (2013). A systematic review of business and information technology alignment. ACM Transactions on Management Information Systems.

[19] Bergeron, F., et al. (2004). Ideal patterns of strategic alignment and business performance. Information \& management 41(8): 1003-1020

[20] Hirschheim, R., \& R. Sabherwal (2001). Detours in the path toward strategic information systems alignment. California management review 44(1): 87.

[21] Silvius, G. A., et al. (2013). The relationship between it outsourcing and business and it alignment: An explorative study. Computer Science and Information Systems 10(3): 973-998.

[22] Luftman, J., et al. (1999). Enablers and inhibitors of business-IT alignment. Communications of the AIS 1(3es).

[23] Gongolidis, E., Evangelia, K., Loucopoulos, P., \& Christos, K., (2016). November. migrating egovernment services in the cloud: A capability modelling approach. Proceedings of the 20th Pan-Hellenic Conference on Informatics.

[24] Al-Hujran, O., Al-Debei, M. M., Chatfield, A., \& Migdadi, M., (2015). The imperative of influencing citizen attitude toward e-government adoption and use. Computers in human Behavior.

[25] Khasawneh, R., Rabayah, W., \& Abu-Shanab, E. (2013), May. E-Government acceptance factors: Trust and risk. Proceedings of the 6th International Conference on Information Technology.

[26] Sapienza, H. J., K. G. Smith, \& M. J. Gannon. (1988). Using subjective evaluations of organizational performance in small business research. Entrepreneurship Theory \& Practice.

[27] Henderson, J. C., \& Venkatraman, H. (1999). Strategic alignment: Leveraging information technology for transforming organizations. IBM Systems Journal, 38(2.3), 472-484.

[28] Jorfi, S., \& Jorfi, H. (2011). Strategic operations management: Investigating the factors impacting IT-business strategic alignment. Procedia-Social and Behavioral Science. 
[29] Guzman, I. R., \& Kaarst-Brown, M. L. (2004). Organizational survival and alignment: insights into conflicting perspectives on the role of the IT professional. Proceedings of the 2004 SIGMIS Conference on Computer Personnel Research: Careers, Culture, and Ethics in a Networked Environment.

[30] Van, D. H. B., \& Winter, M. D. (2011). Us and them: A social capital perspective on the relationship between the business and IT departments. European Journal of Information Systems.

[31] Mumford, E. (1979). Computer systems in work design-The ETHICS method: Effective technical and human implementation of computer systems.

[32] Venkatraman, N., \& Ramanujam, V. (1986). Measurement of business performance in strategy research: A comparison of approaches. Academy of Management Review.

Sulaiman Abdulaziz Alfadhel is a PhD candidature in the Plymouth Graduate School of Management, University of Plymouth, Plymouth, UK. His research interests include business-IS alignment, business process management, e-government, software processes, process modelling, and Information system development.

Professor Shaofeng Liu is with Plymouth Graduate School of Management, University of Plymouth, Plymouth, UK. Her current research interests include decision making and intelligent decision support, Knowledge management (knowledge sharing, networking and mobilisation; lean KM), Product and service value chain innovation, business process improvement, resource management and quality management, project management, multi-criteria decision analysis and life cycle assessment, lean and green operations management, sustainable and global supply chain management, business intelligence and ERP systems, business models and digital business.

Festus Oluseyi Oderanti is a senior lecturer in information systems at University of Hertfordshire Business School. Hi research areas are decision support systems for logistic operation, decision making under uncertainty, strategic business games, fuzzy logic, decision making in networks, eBusiness development, sustainable and scalable business model for assisted living (ehealthcare) technologies, and game related research in the systems, man and cybernetics area 